\title{
APUNTES HAGIOGRÁFICOS E ICONOGRÁFICOS SOBRE UN MODELO DE SANTIDAD MILITAR: MERCURIO-ABU SEIFEIN, EL MÁRTIR DE LAS DOS ESPADAS
}

\author{
SOME ICONOGRAPHIC AND HAGIOGRAPHIC NOTES CONCERNING \\ A MODEL OF MARTIAL SANCTITY: \\ MERCURIUS-ABU SEIFEIN, THE MARTYR HOLDER OF TWO SWORDS
}

POR

Ramón Teja* y Silvia Acerbi ${ }^{*}$

\section{RESUMEN - ABSTRACT}

En el presente artículo proponemos un breve análisis del canon figurativo relativo a Abu Seifein, más conocido como San Mercurio, un mártir militar del siglo III, haciendo especial hincapié en las armas del santo tal como aparecen en la iconografía oriental y occidental. El epíteto con el que se le conoce en ámbito copto hace referencia a las dos espadas, una humana, la otra divina, con las que es representado en el acto de acabar con la vida de Juliano, el emperador apóstata. Sin embargo, se evidencian otras variantes iconológicas, muy pobres en detalles en lo que se refiere a las armas y a la stratiotike esthes si las comparamos con los tratados militares bizantinos contemporáneos.

In this paper we propose a short analysis of the iconographical canon related to Abu Seifein, best known as Saint Mercurius, a military martyr of the III rd. century, focusing specially on the saint's weapons just as this appears in the Western and Eastern iconography. The epithet under with he is known in the Coptic sphere makes reference to the two swords, the human and the divine one, with which he is represented in the act of killing the emperor Julian the Apostate. There are, however, some other iconographical variants, very poor in details as far as the weapons and the stratiotike esthes are concerned, if we face them up to the contemporary military Byzantine treatises.

\section{Palabras Clave - Keywords}

Santos militares; Iconografía; San Mercurio; Armadura.

Military saints; Iconography; Saint Mercurius; Armor.

Abu Seifein es el calificativo árabe con el que desde la época alto-medieval es conocido en Egipto uno de los santos militares más venerados en la Iglesia Copta ortodoxa. El «padre de las dos espadas» es Mercurio, un 'enigmático'1 mártir pre-niceno que vivió y murió bajo el reinado de los emperadores Decio o Valeriano, responsable, según una compleja tradición

* Ramón Teja, catedrático de Historia Antigua de la Universidad de Cantabria - Silvia Acerbi, Profesora Titular de Historia Antigua de la Universidad de Cantabria, Dep. de Ciencias Históricas, Av. de de los Castros s/n, 39005 Santander; tejar@unican.es-acerbis@unican.es.

1 Así lo define Sauget 1967: 365, que traza el más completo perfil histórico-hagiográfico de este legendario mártir. 
hagiográfica que ha dejado una huella significativa en la iconografía oriental y occidental, de la muerte del emperador Juliano el Apóstata².

Las versiones más antiguas de su vida y passio $^{3}$ se consideran redactadas en el siglo VI, cuando en razón de un proceso de progresiva militarización de la sociedad de un Imperio cuyas fronteras iban disolviéndose bajo la presión de pueblos limítrofes (Longobardos, Eslavos, Árabes) $)^{4}$, el culto de los santos militares — soldados que, en la época de las grandes persecuciones, habían abjurado del paganismo, eligiendo morir como confesores de Cristo 5 - había empezado a difundirse tanto en la pars Orientis como en la pars Occidentis de la ecumene cristiana $^{6}$.

Intentando una síntesis entre las noticias de la tradición copta, recogidas en el Synaxarium $^{7}$, y la passio griega, definida por su primer y escéptico editor, Delehaye, «un récit de fantaisie fait de réminiscences et de lieux communs $»^{8}$, intentamos resumir la vida de Mercurio. Durante una cacería el padre del santo, un oficial del ejercito romano originario de Escitia, llamado Yares, y el padre de éste, se encontraron con dos seres feroces que devoraron al más anciano y hubieran hecho lo mismo con Yares si un ángel no hubiese intervenido para salvarlo, domando las fieras (descritas en algunos relatos como cinocéfalas). Convertido al cristianismo con el nombre de Noah, supo que a él y a su esposa Saphina, que vivían entonces en Eskentos, en Capadocia, les iba a nacer un hijo, Philopater, destinado a ser «árbol de frutos generosos». A la muerte del padre, el joven, bautizado con el nombre de Mercurio, lo remplazó en las filas del ejército imperial: mientras luchaba como soldado en la militia de los Martenses, recibió la visión del arcángel Miguel que le hacía el don de una espada, prometiéndole grandes victorias si se mantenía fiel al Señor. El joven combatió valerosamente contra los bárbaros, matando a su rey, y como premio fue honrado por el emperador con el título de stratelates. La envidia de otros soldados le delató como cristiano a Decio, que en el 249 había dado comienzo a una nueva persecución. Nuevamente exhortado por un ángel a no apostatar de la fe verdadera, se negó a ofrecer sacrificios a la diosa Artemisa. Encarcelado y torturado, arrojó sus armas y el uniforme, la clámide y el cinturón, afrontando con sólo veinticinco años el martirio por decapitación en Cesarea de Capadocia, la ciudad que será asociada a su culto y donde tendrán lugar sus primeros milagros. Ya en el segundo decenio del siglo VI, poco después de la muerte del emperador Anastasio I, Theodosius, en su Itinerarium Hierosolymitanum, deja constancia de la visita llevada a cabo al santuario del mártir en Cesarea y de la devoción que le profesaban los capadocios?.

Este relato hagiográfico, que tiene numerosos puntos en común con el de otros mártires militares (el despojarse de las insignias del status militar recuerda el martirio de los santos

Büttner-Wobst 1892: 561-580.

Passio griega premetafrastica (BHG, 1274) en Delehaye 1909: 234. Ibidem: 243-258 se encuentra la versio de Simeón Metafrastes; para una versión posterior de la Passio (BHG 1275) v. Binon 1937: 27-39; también la Oratio de Nicephorus Gregoras (BHG 1277) se encuentra en Binon 1937: 67-91.

4 Darkó 1939, Ostrogorsky 1960, Pertusi 1968, Mitchell 1981, Carile 1984 y 1989, Ravegnani 1988 y 2004.

5 Delehaye 1966b y 1966c, Fontaine 1980: 141-171, Webster 1980, Swift 1983, Brock 1988, Brennan 1990, Fernández Ubiña 2000.

6 Sobre santidad militar son fundamentales las monografías de: Orselli 1993, Brock 1988, Woods 1999; más divulgativo el trabajo de Cammilleri 1992.

7 Wüstenfeld 1879: 135.

8 Delehaye 1909: 234. El relato completo de la Passio (BHG 1274) traducido al inglés se puede leer en Wood 1999: http://www.ucc.ie/milmart/BHG1274.html.

9 Theodosius, Itinera Hierosolymita, ed. Maraval 1996: 194. Sorprende en cualquier caso que en los principales centros espirituales de la ortodoxia bizantina —Constantinopla, Jerusalén, Antioquía, Alejandría - no hubiese iglesias consagradas al santo; aun así parte de sus reliquias que incluyen restos de su armamento se conservan en el Monasterio de Dionysiou, y en el del Pantocrator, ambos en el Monte Athos. 
Sergio y Baco; la espada que lo hace digno de vencer al enemigo tiene un claro paralelismo en un episodio contenido en el bios de san Procopio) se superpuso a la leyenda de Mercurio como autor de la muerte de Juliano el Apostata, emperador de Oriente entre los años 360 y 363.

En el último siglo numerosos estudiosos han dedicado su atención al análisis de las fuentes historiográficas, paganas y cristianas, con el propósito de aclarar las circunstancias de la misteriosa muerte de Juliano en el frente persa ${ }^{10}$. El hecho de que, entre las diversas versiones que corrieron sobre el autor de esta muerte, en una de ellas se atribuyese a un soldado cristiano del sequito imperial, dio lugar a la llamada «leyenda de san Mercurio» recogida por vez primera por el historiador Malalas (siglo VI). Según Malalas el obispo de Cesarea, Basilio, que había tenido estrecha relación con el princeps durante su juventud, tuvo el privilegio de una visión la misma noche de la muerte de Juliano: «Aquella noche el muy santo Basilio, obispo de Cesarea, contempló en una visión los cielos abiertos y al salvador Cristo sentado en el trono que decía a gritos: «Mercurio, sal, y da muerte a Juliano, el emperador persecutor de los cristianos». El santo Mercurio, puesto de pie delante del Señor llevando una coraza de hierro, al escuchar la orden quedó sin voz. Y de nuevo apareció delante del trono del Señor y gritó: «Juliano, el emperador, ha muerto asesinado, como ordenaste, Señor». Al escuchar la voz el obispo Basilio se despertó sobresaltado. A la mañana siguiente durante el servicio litúrgico, reunió a todos sus clérigos y les contó el misterioso sueño, y que el emperador había sido fatalmente asesinado esa misma noche. Todos le pidieron que lo mantuviese en secreto y que no se lo dijese a nadie» ${ }^{11}$. La versio de Malalas será reproducida verbatim poco después por el anónimo autor del Chronicon Paschale ${ }^{12}$.

«Un complejo dossier hagiográfico» ${ }^{13}$ compuesto por textos $\operatorname{coptos}^{14}$ e incluso iraníes ${ }^{15}$ añade a este relato detalles todavía más novelescos, como el del gladius que, desaparecido de la iglesia, había vuelto a su sitio la mañana siguiente manchado de la sangre del emperador.

El culto de Mercurio se difundió por todo el imperio, pero la iconografía del santo militar conoció significativas diversificaciones según las áreas geo-culturales ${ }^{16}$.

El prototipo figurativo presente en la tradición icónica bizantina —en la que casi nunca agios Merkurios es representado como justiciero del emperador Apóstata- es similar al de otros santos militares normalmente reproducidos en postura erecta ${ }^{17} \mathrm{o}$, más raramente, ecuestre, con uniforme y armas. Una de las representaciones más antiguas (primer cuarto del siglo $\mathrm{X}$ ) se encuentra en Capadocia, en la Direkli Kilise: el santo, que viste un uniforme militar muy inusual, esgrime una espada en la mano derecha ${ }^{18}$. En Yeniköy, en la basílica de Constantino, aparece caracterizado con coraza, túnica roja y clámide azul, con una lanza y un escudo redondo. El fresco es del siglo XI, como el de la Iglesia de santa Bárbara, donde el escudo parece colgar de la espalda del militar ${ }^{19}$. Siempre en Capadocia, en la Karabas Kilise, Mercurio blan-

10 Recientemente se han ocupado del tema Bouffartigue 2006, y Teja-Acerbi 2009. A cerca de la presencia de Mercurio en la historiografía eclesiástica del siglo V, v. Orselli 1990: 120sg. Interesante también el trabajo de Muhlberger 1998: 83-98.

11 Malalas XIII, 21-22 (ed. Dindorf); v. también Krappe 1928: 1029-1034.

12 Chronicon Paschale 52 (ed. Dindorf).

13 Así lo define Boulhol 2004: 111, que analiza algunas de las fuentes disponibles.

14 Orlandi 1968: 87-145; Idem 1976: 54-60.

15 Azarnoush 1991: 322-329.

16 Brennan 1990; desafortunadamente no hemos podido consultar el trabajo de Curta 1995:109 sg.

17 Orselli 1993: 5 recuerda que la postura erecta, que evoca la actitud de las presencias angélicas en la Biblia, responde a un léxico exquisitamente visionario cuyo núcleo semántico es el verbo griego paristemi en latín adsto/adsisto).

18 Thierry 1967: 87.

19 Jolivet-Lévy 1991: 282. 
de lanza y escudo, y en la capilla dedicada a la Theotokos de la Iglesia de San Juan Batista y San Jorge, cuya datación es difícil de establecer, viste un uniforme corto ${ }^{20}$.

El santo es representado sólo en tres de los trípticos ebúrneos del siglo X, y cada vez con atributos militares distintos: en el de Harbaville, así como en tríptico del Hermitage aparece en forma de medio busto, llevando en el primero un escudo y en el segundo la lanza ${ }^{21}$; en otro conservado en el Museo Vaticano viste la stratiotike esthes, sin armas.

Sorprende hasta qué punto la iconografía del equipamiento militar es pobre de detalles y que, observa Maria Parani, no exista una específica combinación de armas asociadas a un mártir militar, normalmente identificado, cuando falta la explícita indicación del nombre, por otros elementos figurativos, como por ejemplo los rasgos prosopográficos ${ }^{22}$.

Sin embargo en el caso de Mercurio aparece un elemento peculiar, ausente en las representaciones de los demás milites Christi: se trata del yelmo. Esta originalidad podría explicarse con una continuidad figurativa de Mercurio con la homónima divinidad pagana representada, a partir del Renacimiento, con yelmo ${ }^{23}$. La tipología del morrión que, desde el siglo XVI, se transformará en el signo distintivo de este modelo de santidad militar, se encuentra en numerosos retratos serbios y macedonios, como por

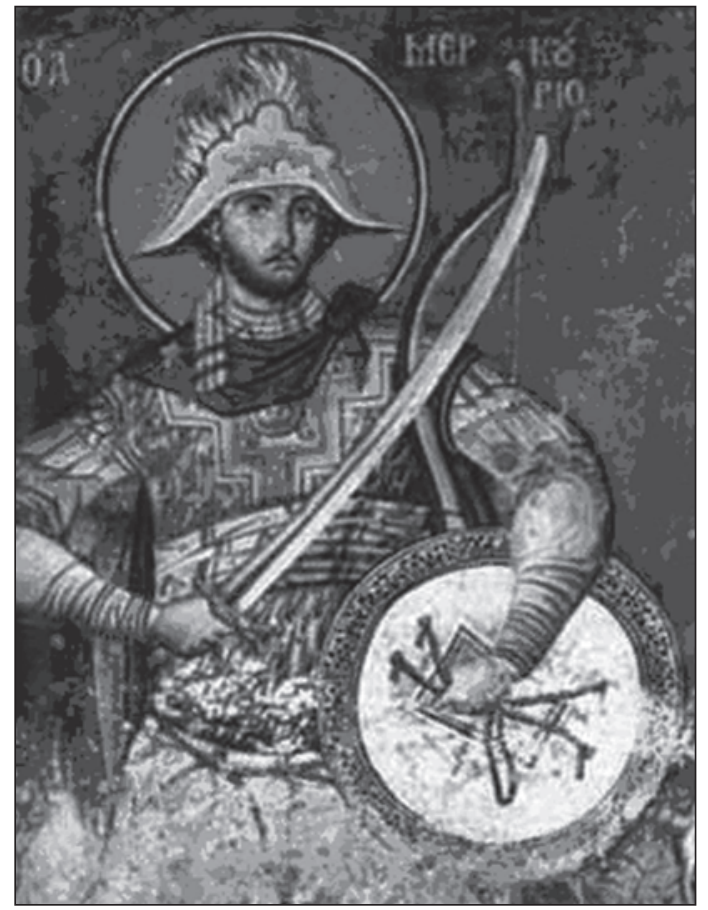

Figura. 1. Icono Búlgaro (siglo XV). ejemplo el de la Iglesia de San Clemente, en Ohrid, del siglo XIII, o el de la Iglesia de los Santos Apóstoles, en Pec, del siglo XIV. El yelmo del santo capadocio a veces tiene plumas o adornos en los laterales, como el del mensajero de los dioses (fig. 1). En el Monasterio de Dečani, en Serbia, es representado con yelmo pero sin espada y sin escudo, substituidos por arco y flechas.

Sin yelmo y como soldado a pie Mercurio es representado en los mosaicos del siglo XI de la Iglesia de Hosios Lukas cerca de Livadia, en Grecia, y en los de Kariye Djami, en Estambul. En este último viste una coraza de bronce, y como cingulum alrededor del tórax una banda de metal ${ }^{24}$. También sus brazos y muslos están protegidos por mallas metálicas y alrededor del cuello tiene un collar de cuero ${ }^{25}$.

En el icono del Tesoro de S. Marcos en Venecia, del siglo XII, junto al arcángel Miguel en figura entera, en el centro, con la espada en la mano derecha y el globo crucífero

20 Jerphanion 1925: I, 124.

21 Goldschmidt-Weitzmann (1934): II,34-35; Banck 1984: 141-147.

22 Parani 2003: $150 \mathrm{sg}$. La estudiosa griega estudia «the military costume» (101sg.) analizando con gran precisión cada una de las armas representadas en la iconografía religiosa y civil entre los siglos XI y XV. Cfr. Kolias 1988 y Treadgold 1995.

23 Es necesario precisar que el Hermes antiguo nunca lleva casco, sino el sombrero de caminante que conocemos como pétaso: fueron ciertos artistas del Renacimiento los que, al no saber interpretar este tocado, le dieron a veces la forma y textura metálica de un yelmo.

24 Underwood 1967:157.

25 Idem: 256. 
en la izquierda, Mercurio es representado en un esmalte oval junto a san Eustaquio con una lanza en la mano derecha, y un escudo en la izquierda. La iconografía se repite en un fresco del siglo XVI en Moldavia (en el monasterio Sucevita) y en uno del siglo XVIII en Serbia (monasterio de Krusedol, a sudeste de Novi-Sad).

Muy raro es en el arte bizantino el motivo iconológico de Mercurio ecuestre, más tardío, y distintivo, en la mayoría de los casos, de un contexto cultural y religioso islámico ${ }^{26}$. Una excepción la constituye un fresco del siglo XIV de un monasterio de Moldavia: Mercurio y Demetrio son representados en el acto de vencer cada uno a un emperador enemigo de los cristianos: el primero a Juliano, el segundo a Maximiano ${ }^{27}$.

Mientras indudablemente en la iconografía bizantina Mercurio tiene un papel secundario respecto al de otros santos militares con un rango jerárquico superior al suyo - San Jorge y San Demetrio, pero también los dos Theodoros (Teodoro Stratelates y Teodoro Tirone), San Eustaquio y San Menas - en ambiente monofisita, especialmente en el Valle del Nilo, adquirió a partir del siglo IX una extraordinaria relevancia. En este contexto el santo frecuentemente aparece asociado al episodio de la muerte del emperador Juliano quien figurativamente asume la ubicación del dragón en la iconografía de san Jorge sauroctonos, humillado y vencido a los pies del mártir. Quizás fue la tradición de sus hazañas en contra del Apóstata lo que lo convirtió en símbolo de valentía y voluntad de rescate en un Egipto oprimido por la dominación islámica. Lo cierto es que en el outillage copto-ortodoxo, entre los siglos IX y XI, el nombre del mártir Markûrah se perpetuó en las jerarquías eclesiásticas, monásticas y civiles, y ya antes de la fractura político-religiosa provocada por la invasión árabe, había más de veinticinco iglesias dedicadas al mártir (la más conocida es la Iglesia de San Mercurio dentro del recinto del homónimo monasterio, en el viejo El Cairo) ${ }^{28}$. Y muchos eran los monasterios a él consagrados (al menos cuatro en el Valle del Nilo $^{29}$ ) en los que se veneraban sus reliquias y se celebraban solemnidades litúrgicas en su memoria.

Una de las representaciones coptas más antiguas de Mercurio caballero es un fresco conservado en la Iglesia de Faras en Nubia, probablemente del siglo IX, que lo presenta a caballo en el acto de penetrar al emperador Juliano con una lanza. También en la pared meridional del coro de la Iglesia de San Antonio, en el Monasterio de San Antonio del Mar Rojo, se encuentra un fresco (fig. 2), realizado entre el siglo X y el XIII, que muestra al santo subido sobre un caballo ricamente adornado: con la mano derecha sostiene una lanza que atraviesa al emperador caído a sus pies, y con la izquierda agarra una espada que un ángel — verosímilmente el arkistrategos san Miguel- le está tendiendo. Detrás de la pata izquierda del caballo se reconoce una figura humana atacada por dos cinocéfalos (evidente referencia, rica, como veremos, de significado, a la notitia del Sinaxarium copto).

La iconografía más común de San Mercurio a partir del siglo XVIII es la de un joven sin barba o con pequeños bigotes que monta, por la derecha o por la izquierda, un caballo oscuro. El santo, que lleva un uniforme de soldado con la capa flotando al viento, empuña, una en cada mano, sendas espadas, la humana y la divina, que se cruzan detrás de su cabeza. Con la derecha sujeta también una larga lanza que golpea la corona del emperador Juliano, derribado por su caballo blanco. En alto a la derecha aparece San Basilio en hábito episcopal. Un ejemplo

\footnotetext{
26 Lewis 1973: 27-63, cfr. también Walter, 1989: 657-673 que estudia la tipología del ‘horseman' en el contexto cultural de Tracia.

27 Henry 1930: 230.

28 Meinardus (1965): 240 sg. e Idem 1972-1973: 116-117 recuerda una Iglesia en Harat Zuwailah, otra en Al Wali, y otra en Al-Sahl.

${ }_{29}$ Meinardus (1972-1973): 116 menciona el Monasterio de San Mercurio en Tammuah, el de Dair Shahran, el de Al-Hawatka y el de Higaza.
} 


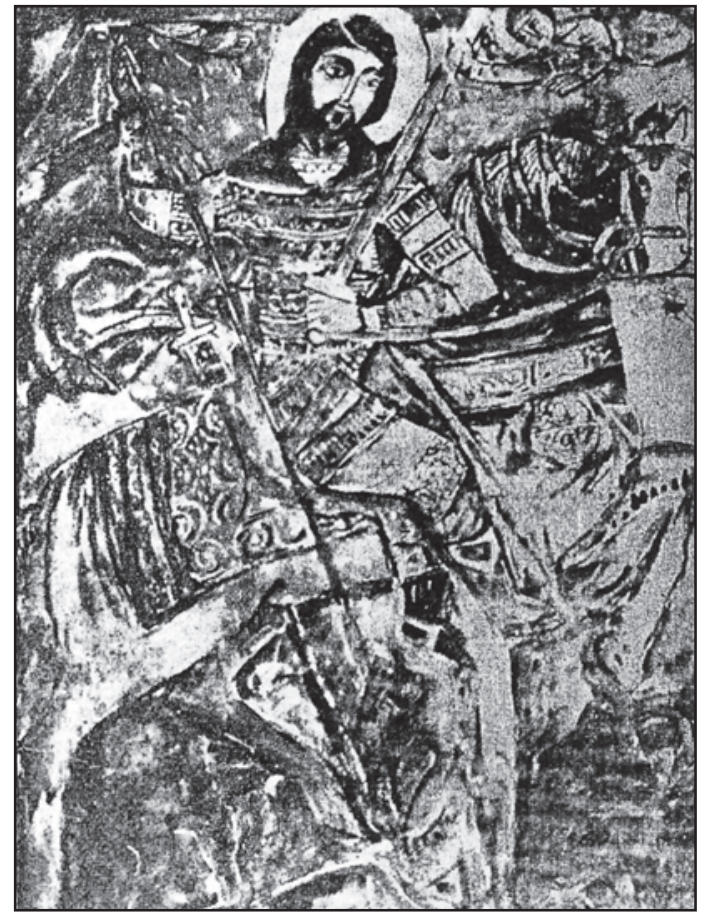

Figura 2. Iglesia de San Antonio, Monasterio de San Antonio del Mar Rojo, fresco del siglo X.

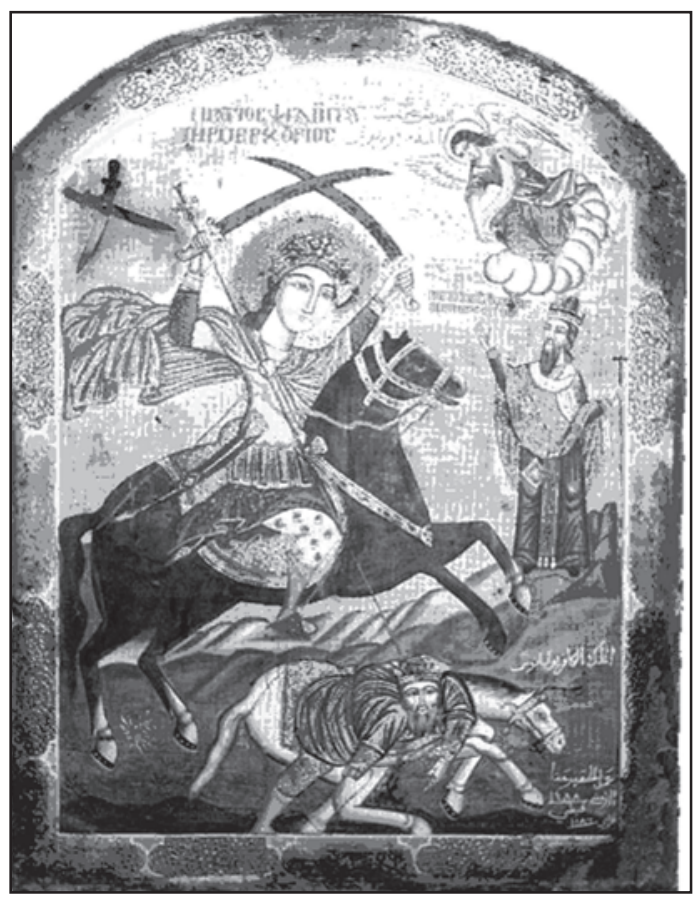

Figura 3. Abu Seifein, icono en la Iglesia de San Mercurio - Monasterio de San Mercurio en El Cairo.

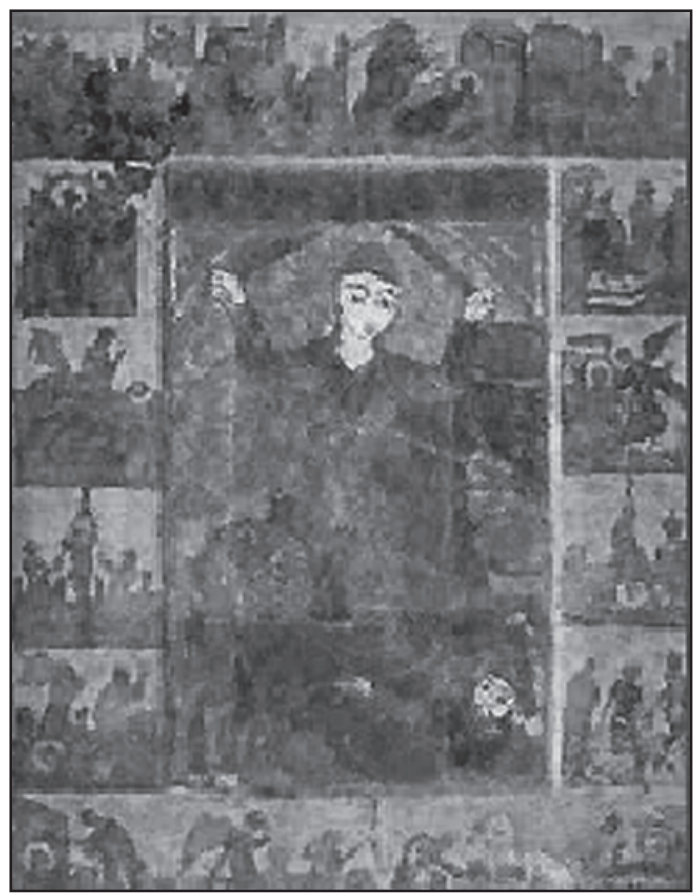

Figura 4. Icono copto, siglo XI. 


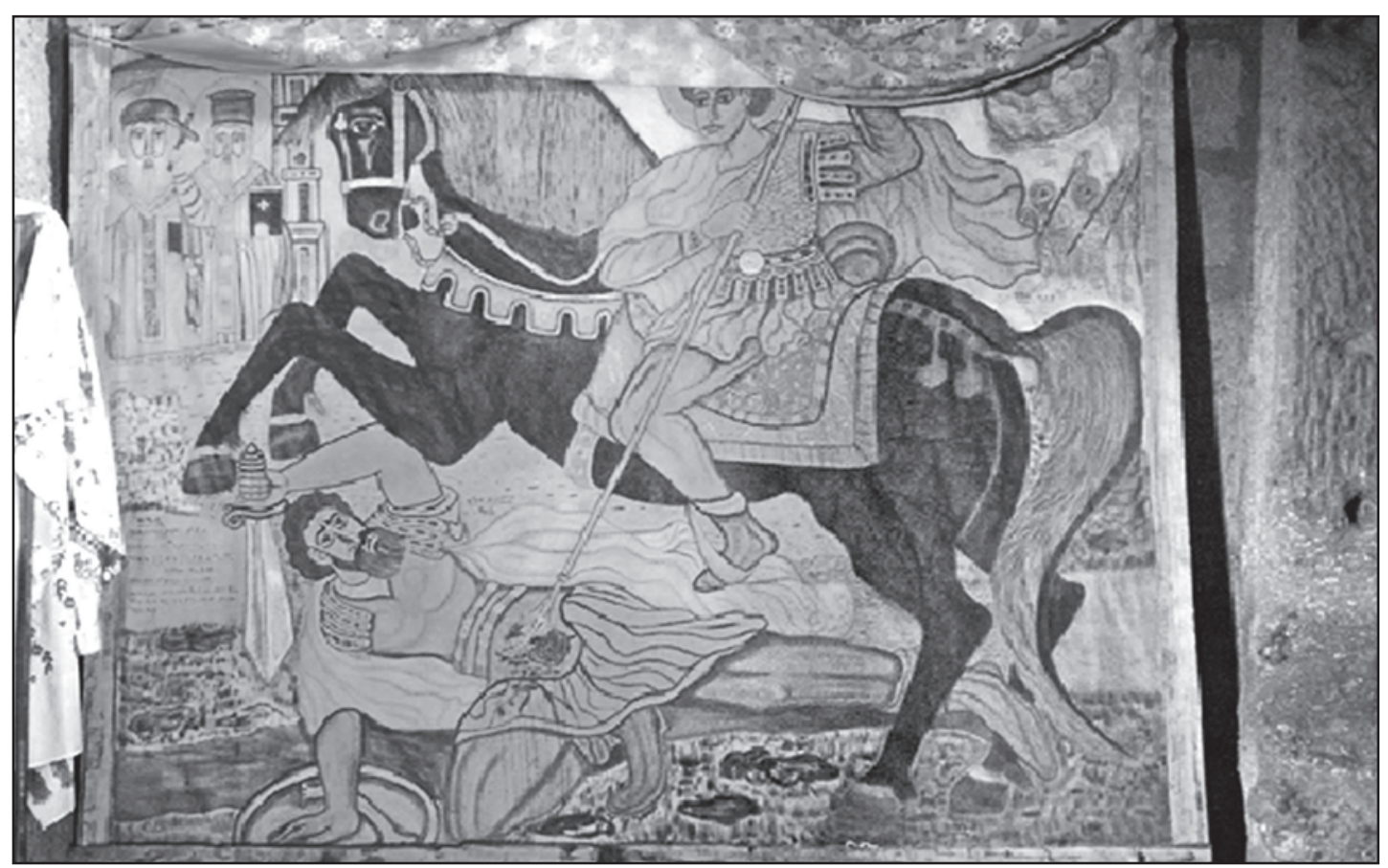

Figura 5. San Mercurio matando al rey Oleonus (Juliano) - Iglesia de Bet Markorios en Lalibela (Etiopía)..

elocuente de esta tipología es el icono conservado en la Iglesia de San Mercurio, dentro del recinto del Monasterio homónimo en el viejo El Cairo (fig. 3) ${ }^{30}$.

San Merkorewos/Markorios es muy venerado también en la Iglesia Ortodoxa de Etiopía. En las colinas que rodean la ciudad de Lalibela, la antigua Roha, capital de la dinastía Zagwe entre los siglos X-XIII, en un área que abarca unos siete kilómetros cuadrados, se encuentran doce iglesias, casi invisibles a los visitantes en virtud del método constructivo empleado (fueron talladas «hacia abajo» en una roca basáltica rojiza, transformándose en verdaderas esculturas monolíticas interconectadas entre sí por hipogeos, túneles, pasadizos y trincheras). La iglesia dedicada a Bet Markorios, emplazada en una cava preexistente, conserva frescos del siglo XV que por estilo y cromatismo se alejan del repertorio iconográfico etiope-ortodoxo ${ }^{31}$. En uno de ellos Mercurio, montando un caballo negro, aparece en el acto de traspasar con su lanza al rey Oleonus, nombre que en dialecto amárico corresponde al del emperador Juliano (fig. 5). El santo, representado con rasgos etíopes y vestimenta militar, no lleva espada. Su víctima, Juliano, es quien intenta levantar la spathe mientras la lanza de Mercurio le traspasa los intestinos. Atraen la atención, en la parte derecha del fresco, unas figuras en hábito militar que no parecen tener rasgos humanos. Una obra contemporánea, ejecutada en un estilo pictórico muy convencional por un artista local, Adamu Tesfaw, confirma que los soldados que acompañan al santo y que componen su singular militia son cinocéfalos $^{32}$ (fig. 6).

El mito de los hombres-perros, presente en todas las culturas indoeuropeas desde el África septentrional hasta la Grecia, desde la Persia hasta la India hizo su ingreso en la literatura hagiográfica a través de las Actas apócrifas de San Andrés y Bartolomé, descritos en misión

30 En algunos iconos coptos las dos espadas no aparecen cruzadas (fig. 4).

Raineri, 1996.

32 Piankoff 1942: 17-27. Sobre los cinocéfalos v. Gordon White 1991: 37-38 y 227 n. 75, Bartlett, $2008:$ 71-110. 


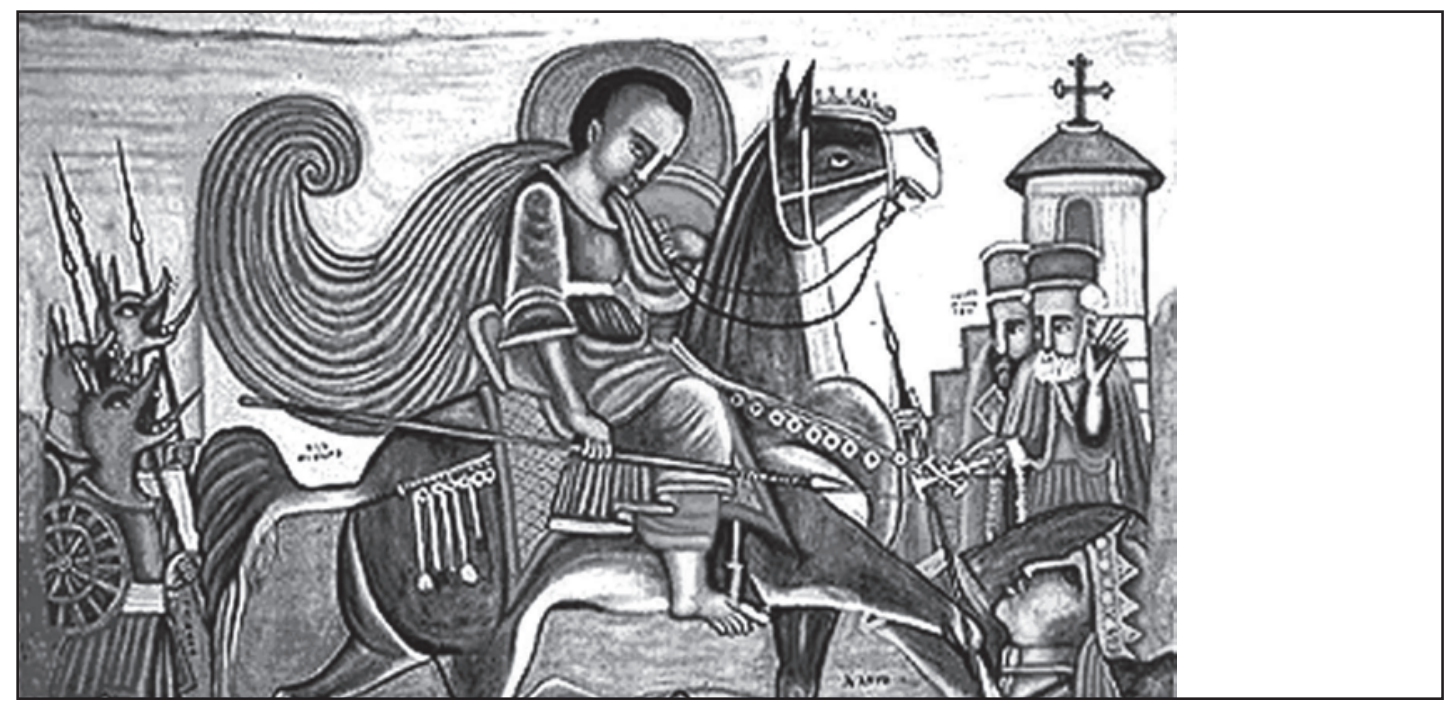

Figura 6. Adamu Tesfaw, artista etíope contemporáneo: Mercurio y Juliano.

apostólica en las regiones del Mar Negro. De allí, de Bitinia, era también san Cristóbal ${ }^{33}$, un cinocéfalo convertido al cristianismo que en muchos iconos y frescos bizantinos muestra rasgos comunes al dios egipcio Upuaut y sobretodo a Anpu (Inpu, Ienpu, Imaut o Imeut; Anubis es su nombre helenizado). En época romana imperial está documentada la iconografía de Anubis con cabeza de cánido y armadura: aparece dos veces, por ejemplo, en la necrópolis de Kom el Shugafa, en Alejandría. Su sentido, obviamente, es apotropáico, y muestra al dios funerario como protector de los muertos y su morada subterránea. Así como Ampu, dios psicopompo, era encargado de guiar los espíritus de los muertos al "otro mundo", la Duat, Cristóbal cinocéfalo cruzaba el río llevando al niño Jesús en sus hombros. Resulta interesante que los escritores griegos asociasen a Anpu con el dios Hermes del que san Mercurio sería la 'encarnación' cristiana. Lo que sorprende en estos frescos es la trasformación de los cinocéfalos en soldados de la milicia de Mercurio. Tema iconológico, éste de los milites con cabeza de perro, que seguirá teniendo gran fortuna en Oriente hasta época más tardía (fig. 7).

Profundas interacciones culturales y simbólico-iconográficas entre las regiones orientales del Imperio y las áreas de la Italia centro-meridional hicieron que el culto de san Mercurio se concentrara principalmente en el sur de la península itálica. Como recuerda Antonio Vuolo en un trabajo sobre la hagiografía medio-latina en la Italia meridional ${ }^{34}$, se cree que parte de las reliquias de San Mercurio fueran trasladadas a Italia junto con otros cuerpos santos por Constante II, en el 663, para que le propiciaran una victoria contra los longobardos ${ }^{35}$. Asediada sin éxito la ciudad de Benevento, el emperador tuvo que dejarlas en Quintodecimo, la antigua $\mathrm{Ae}$ clanum, un pueblo en la provincia de Avellino. Ciento cinco años más tarde, exactamente el 26

33 La Passio Sancti Christophori Martyris se encuentra en Analecta Bollandiana 1, 1882: 394-405 [BHL 1764].

34 Vuolo, 1996: 211.

35 Relato anónimo de la traslatio de las reliquias de Mercurio desde Quintodecimo a Beneventum, AD768 en Monumenta Germaniae Historica: Scriptores Rerum Langobardicarum et Italicarum, Saeculi VI-IX (Hannover, 1878), 576-578 [BHL 5936]. Cfr. Delehaye 1966: 189-195, quien pone en duda, como ya los Bolandistas, que el Mercurio cuyas reliquias fueron trasladas de Quintodecimo a Benevento fuera un homónimo santo originario de Aeclanum. 


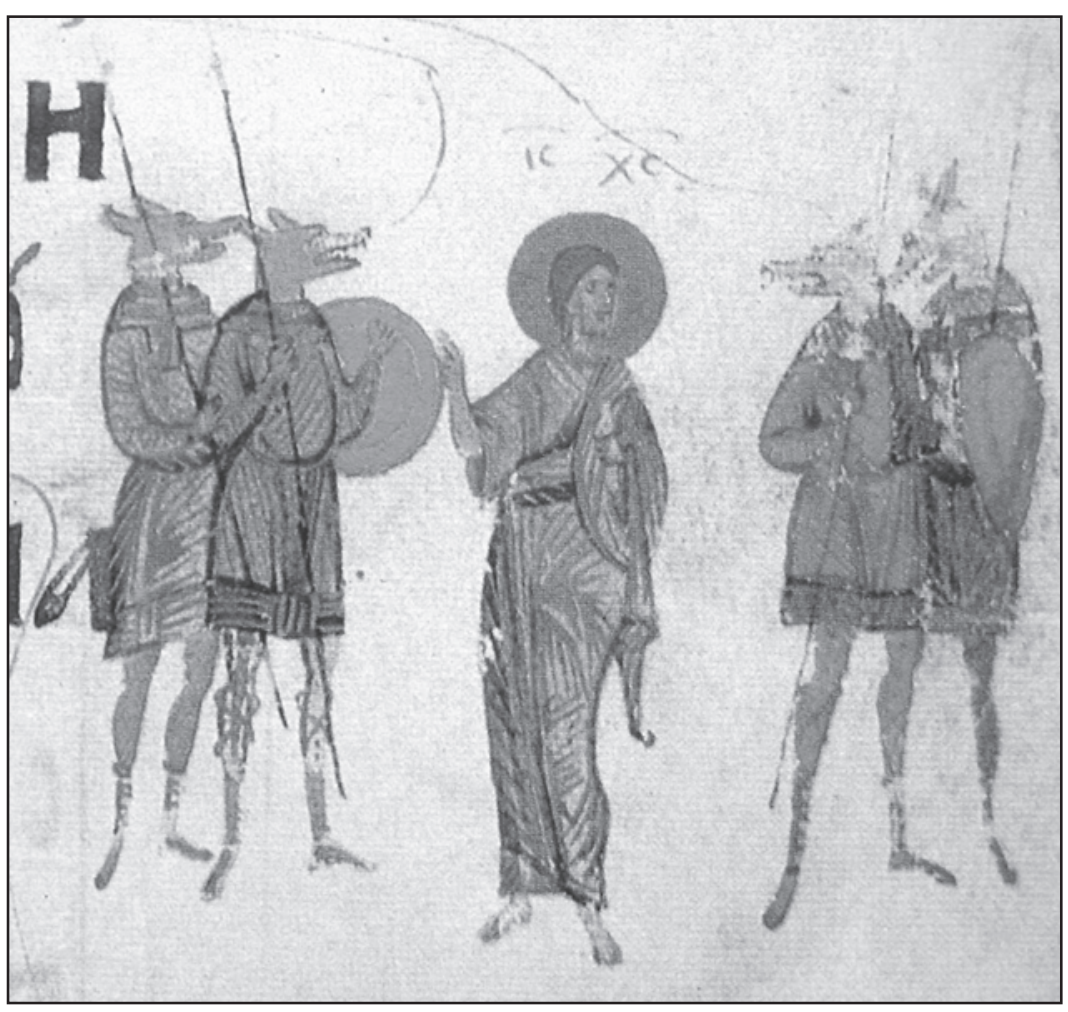

Figura 7. Soldados cinocéfalos, Salterio de Kiev, siglo XIV.

agosto del 768, será el rey Arequis, muy devoto al santo ${ }^{36}$, quién las trasladará a Benevento, al altar principal del opulentissimum templum de Santa Sofia. Mercurio se convertirá en domini eiusdem loci tutor et urbis, patrono de la ciudad y del entero ducado.

La iconografía de San Mercurio como justiciero del Apóstata tuvo difusión también en otra región del centro-sur de la península itálica, el Molise. En la catedral de la ciudad de Larino, en la pared de la cuarta 'campata' septentrional, al lado de un fresco, datado en siglo XIV, del arcángel san Miguel apoyado a una grande espada, se encuentran los fragmentos de una representación de San Mercurio en los que se pueden divisar las patas delanteras de un caballo montado por un jinete cuya larga lanza alcanza el cuello de un hombre tumbado en el suelo: su túnica roja y la corona revelan que se trata del emperador Juliano (fig. 8). En la ciudad de Toro, de la que el santo es protector, se conserva un óleo originariamente ubicado en una iglesia del siglo XIV dedicada al mártir (destruida en el terremoto del 1805 y nunca reedificada) cerca de la actual plaza de san Mercurio, que atestigua la devoción popular hacia el santo capadocio. Todavía más al sur, en Seminara, provincia de Reggio Calabria, un bonito bajorrelieve del siglo XV, conservado en la basílica de la 'Madonna dei Poveri', ilustra la escena acostumbrada (fig. 9): una vez más es una larga asta puntiaguda la que acaba con la vida del Apóstata mientras no queda huella de las dos espadas.

36 Vuolo 1996: 213 explica esta devoción del langobardus dux con el carisma ejercido por un santo militar sobre una estirpe muy belicosa que interpretaba en clave cristiana la mítica figura del dios Wodan, el dios guerrero de la antigua religión longobarda. Como escribe Pablo el Diácono en la Historia Langobardorum «Wothan ipse est qui apud Romanos Mercurius dicitur et ab universis Germaniae gentibus ut deus adoratur». La tradición hagiográfica considera a Arequis responsable de la difusión de la Passio latina de S. Mercurio derivada de la griega. 


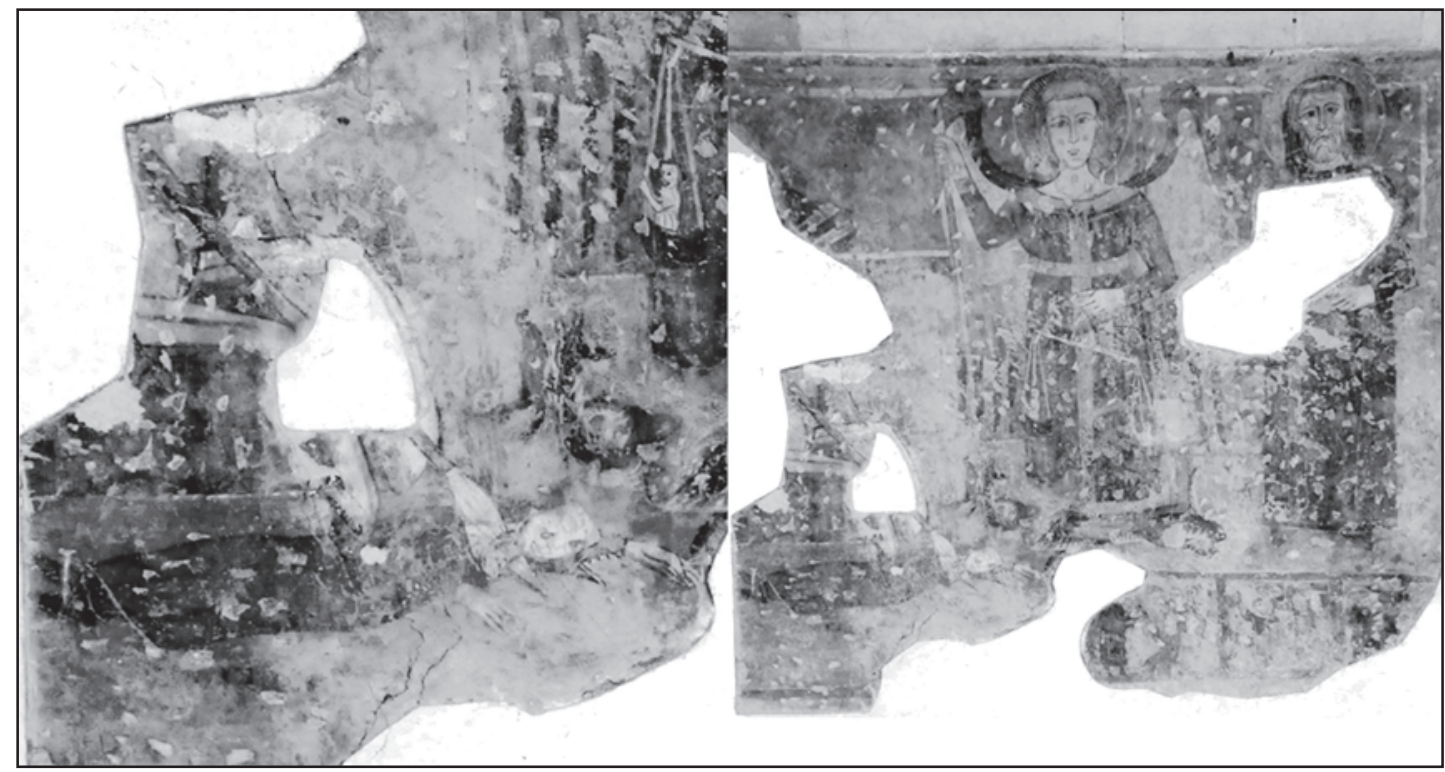

Figura 8. Frescos del siglo XIV, Catedral de Larino (Molise, Italia).

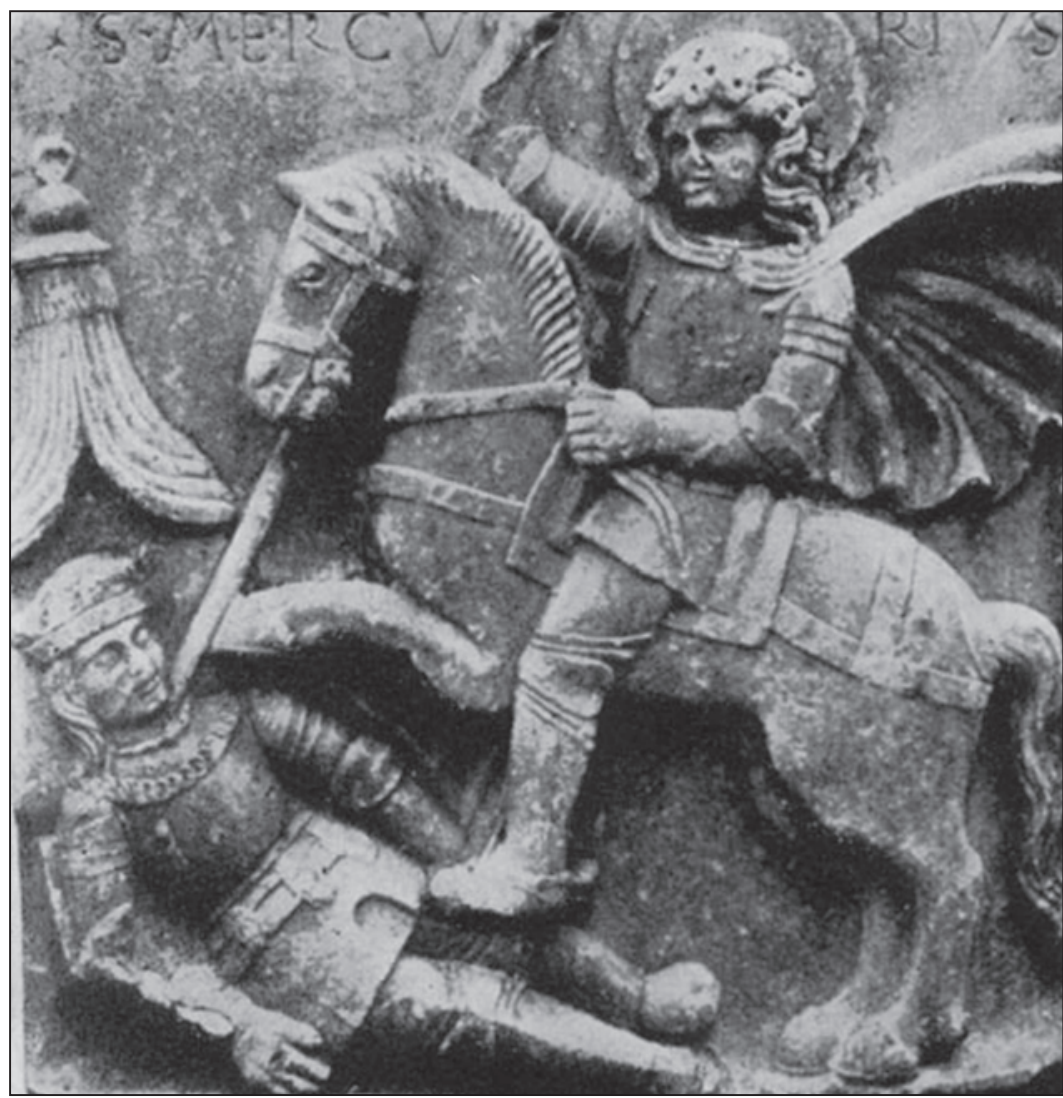

Figura 9. Bajorrelieve del siglo XV. Seminara, provincia de Reggio Calabria, basílica de la 'Madonna dei Poveri'. 
Este breve recorrido por textos e imágenes muestra cómo Mercurio se transformó en un modelo de santidad militar que se refleja en tipos iconográficos cargados, en las distintas regiones del Imperio, de significados tanto políticos como ideales y que traducen un aspecto de la articulada especificidad ideológico-religiosa de la Ecumene cristiana mediterránea en época tardo antigua y medieval desde Oriente hasta Occidente.

\section{BIBLIOGRAFÍA}

Azarnoush, M. (1991): «La mort de Julian l'Apostat selon les sources iraniennes» Byzantion 61: 322329.

Banck, A. (1984): Byzantine Art in the Collections of the URSS, Moscu.

Bartlett, R. (2008): «Dogs and Dog-heads: The Inhabitants of the World», en The Natural and the Supernatural in the Middle Ages, Cambridge: 71-110.

Büttner-Wobst, Th. (1892): «Der Tod des Kaisers Iulian», Philologus 51: 561-580.

Binon, S. (1937a): Essai sur le cycle de St Mercure, Paris.

Binon, S. (1937b): Documents grecs inédits relatifs à S. Mercure, Louvain.

Bouffartigue, J. (2006): «Malalas et l'histoire de l'empereur Julien», en S. Agusta-Boularot, etc.

Boularot et al. (eds.), Recherches sur la Chronique de Jean Malalas, vol. II, Paris: 137-152.

Boulhol, P. (2004): «La geste des saints et l'histoire du monde. À propos des sources hagiographiques de Malalas», en S. Agusta-Boularot et al. (eds.), Recherches sur la chronique de Jean Malalas, Paris: 103-116.

Brennan, P. (1990): «Military Images in Hagiography» en G. Clarke (ed.), Reading the Past in Late Antiquity, Rushcutters Bay.

Brock, P. (1988): The Military Question in the Early Church: A Selected Bibliography of a Century's Scholarship, Toronto.

Cammilleri, R. (1992): Santi militari, Casale Monferrato.

Carile, A. (1984): «Terre militari, funzioni e titoli bizantini nel Breviarium», en A.

Vasina (ed.), Ricerche e studi sul "Breviarium Ecclesiae Ravennatis» (Codice Bavaro), Istituto storico italiano per il Medio Evo, Roma: 81-94.

Carile, A. (1989): «La guerra gotica (535-554) nel Delta del Po», en A. Vasina (ed.), Storia di Ferrara, Ferrara, III.2: 627-656.

Charalampidis, C.P. (2001): «Representations of military Saints in the Middle-Byzantine Iconography of Greek Macedonia», Studi sull'Oriente Cristiano 5,2: 193-201.

Curta, F. (1995): «How to do Things with Saints: On the Iconography of St. Mercurius's Legend», Revue romaine d' histoire 34: 109-129.

Darko, E. (1936): «La militarizzazione dell'impero bizantino», en Actes des Congrès internationaux des Études byzantines, Roma : 92-93.

Delehaye, H. (1909): Les Légendes Grecques des Saintes Militaires, Paris.

Delehaye, H. (1966a): «La translatio sancti Mercurii a Beneventum», en Mélanges d'hagiographie grecque et latine, Bruxelles, 189-195.

Delehaye, H. (1966b): «Le refus de servir et l'Église primitive», en Mélanges d'Hagiographie Grecque et Latine, Bruxelles.

Delehaye, H. (1966c): «La persécution dans l'armée primitive», en Mélanges d'Hagiographie Grecque et Latine, Bruxelles.

Fernandez Ubiña, J. (2000): Cristianos y militares. La iglesia antigua ante el ejército y la guerra, Granada.

Fontaine, J. (1980): «Le culte des martyrs militaires et son expression poétique au IVè siècle: l'idéal évangélique de la non-violence dans le christianisme théodosien», Augustinianum 20: 141-171.

Goldschmidt, A. und Weitzmann, K. (1930-1934): Die byzantinischen Elfenbein-skulpturen des X-XIII Jhs., Berlin.

Gordon White, D. (1991): Myths of Dog-man, Chicago.

Henry, P. (1930): Les églises de la Moldavia du Nord des origines à la fin du XVIe siècle. Architecture et peinture, Paris. 
Haldon, J. F. (1979): Recruitment and conscription in the Byzantine army c. 550-950. A Study on the Origins of the «Stratiotika Ktemata», Wien.

Jerphanion, G. (1925) Une Nouvelle Province de l'art Byzantin. Les Églises Rupestres de Cappadoce, Paris.

Jolivet-Levy, C. (1991): Les églises byzantines de Cappadoce, Paris.

Kolias, T. (1988): Byzantinische Waffen, Wien.

Krappe, A. H. (1928): «La vision de Saint Basile et la légende de la mort de l'empereur Julian», Rev. Belgue de Phil. et d'Histoire 7: 1929- 1034.

Lewis, S. (1973): «The Iconography of the Coptic Horseman in Byzantine Egypt», Journal of the American Research Center in Egypt 10: 27-63.

Maraval, P. (1996): Récits des premiers pèlerins au Proche-Orient, Paris

Marco, F. (1987): San Jorge de Capadocia, Zaragoza.

Meinardus, O. (1965): Christian Egypt Ancient and Modern, El Cairo.

Meinardus, O. (1972-1973): «St. Mercurius-Abu’s Saifain. A Study of Cult and Art», Studia Orientalia Christiana 15: 109-119.

Mitchell, S. (1981): Armies et Frontiers in Roman and Byzantine Anatolia. Proceeding of a Colloquium held at University College, Swansea.

Muhlberger, S. (1998) «War, Warlords, and Christian Historians from the Fifth to the Seventh Century», en A.C. Murray (ed.), After Rome's Fall: Narrators and Sources of Early Medieval History, Toronto: 83-98.

Orlandi, T. (1968): «La leggenda di San Mercurio e l'uccisione di Giuliano l'Apostata», en Studi Copti, Milano: 87-145.

Orlandi, T. (1976): Passione e miracoli di S. Mercurio, Milano.

Orselli, A.M. (1990): «Regalità e profezie nella storiografia cristiana tra V e VII secolo», Augustinianum 30, 1: 107-126.

Orselli, A.M. (1993): Santità militare e culto dei santi militari nell' impero dei romani (secoli VI-X), Bologna.

Ostrogorsky, G. (1960): «L'exarchat de Ravenne et l'origine des Thèmes byzantins», en Atti del Corso di Cultura sull'Arte Ravennate e Bizantina, Ravenna, 7: 99-110.

Parani, M.G. (2003): Reconstructing the Reality of Images. Byzantine Materials, Culture and Religious Iconography 11Th-15th Centuries (Medieval Mediterranean), Leiden.

Pertusi, A. (1968): «Ordinamenti militari, guerre in Occidente e teorie di guerra dei Bizantini (secc. VI-X)» en Atti della XV settimana del Centro Italiano di Studi sull'Alto Medioevo (Spoleto, 30 marzo-5 aprile 1967), Spoleto: 631-700.

Piankoff, A. (1942) : «Saint Mercure Abou Seifein et les Cynocéphales», Bulletin de la Société d'Archéologie Copte $8: 17-27$.

Ravegnani, G.(1988), Soldati di Bisanzio in età giustinianea, Roma.

Ravegnani, G. (2004): I bizantini in Italia, Bologna.

Raineri, O. (1996): Santi guerrieri a cavallo: tele etiopiche, Clusone.

Sauget, J.M (1967): «Mercurio di Cesarea», Bibliotheca Sanctorum 9: 365-366.

Swift, L.J. (1983): The Early Fathers on War and Military Service, Wilmington.

Teja, R. y Acerbi, S. (2009): «Una nota sobre San Mercurio el Capadocio y la muerte de Juliano», Antiquité Tardive: Revue Internationale d'Histoire et d'Archéologie 17: 185-190.

Thierry, N. y M. (1963): Nouvelles églises rupestres de Cappadoce, Paris.

Treadgold, W. (1995): Byzantium and its Army (284-1081), Stanford.

Underwood, P. (1967), The Kariye Djami, London.

Vuolo, A. (1996): «Agiografía Beneventana», en VV.AA., Longobardia e Longobardi nell'Italia meridionale, Le istituzioni Ecclesiastiche, Milano: 199-238.

Walter, C. (1989): «The Thracian Horseman: Ancestor of the Warrior Saints?», Byzantinische Forschungen 14: 657-673.

Walter, C. (2003): The Warrior Saints in Byzantine Art and Tradition, Aldershot.

Webster, A.F.C. (1980): «Varieties of Christian Military Saints: From Martyrs under Caesar to Warrior Princes», St. Vladimir's Theological Quarterly 24: 3-36. 
Whitby, M. (1998): «Deus Nobiscum: Christianity, Warfare, and Morale in Late Antiquity», en M. Austin, J. Harries, and C. Smith (eds.), Modus Operandi: Essays in Honour of Geoffrey Rickman, London: 191-208.

Woods, D. (1999): The Military Martyrs: http://www.ucc.ie/milmart/index.html.

Wüstenfeld, F. (1879) Synaxarium das ist Hailigen-Kalendar der Coptirchen Christen, Gotha.

Recibido: 22/10/2009

Aceptado: 25/05/2011 